\title{
Uso de fontes de informação no monitoramento dos ambientes organizacionais: subsídios para o planejamento estratégico em bibliotecas universitárias brasileiras
}

\author{
Everton Rodrigues Barbosa \\ Doutorando; Universidade Federal de Santa Catarina, Florianópolis, SC, Brasil; \\ evertonpos@gmail.com \\ Raquel Alexandre de Lira \\ Doutoranda; Universidade Federal de Santa Catarina, Florianópolis, SC, Brasil; \\ raquelalexandrelira@gmail.com \\ Angel Freddy Godoy Viera \\ Doutor; Universidade Federal de Santa Catarina, Florianópolis, SC, Brasil; \\ godoy@cin.ufsc.br

\section{Gregório Varvakis} \\ Doutor; Universidade Federal de Santa Catarina, Florianópolis, SC, Brasil; \\ g.varvakis@ufsc.br
}

\begin{abstract}
Resumo: O estudo tem como objetivo propor uma categorização das fontes de informação para o monitoramento dos ambientes organizacionais das Bibliotecas Universitárias, levando em consideração que tais recursos informacionais oferecem subsídios para a elaboração do planejamento estratégico. Discute as variáveis ambientais que influenciam na gestão das bibliotecas acadêmicas brasileiras. A pesquisa caracteriza-se como exploratória descritiva, de abordagem qualitativa e quantitativa, e utiliza a pesquisa bibliográfica para o levantamento de publicações. Apresenta as principais fontes, obras e autores mencionados na literatura analisada. Conclui que as fontes de informação podem ser categorizadas conforme três segmentos ambientais: o primeiro orientado à percepção do ambiente geral, o segundo voltado para o ambiente organizacional e o terceiro dedicado ao ambiente interno. Recomenda que trabalhos futuros aprofundem a proposta de categorias, considerando sua efetiva aplicabilidade no monitoramento ambiental e planejamento estratégico.
\end{abstract}

Palavras-chave: Bibliotecas universitárias. Planejamento estratégico. Fontes de informação. 


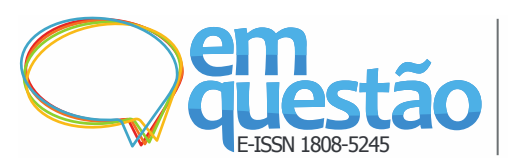

Uso de fontes de informação no monitoramento dos ambientes oraganizacionais: subsídios para o planejamento estratégico em bibliotecas universitárias brasileiras

Everton Rodrigues Barbosa, Raquel Alexandre de Lira, Angel Freddy Godoy Viera e Gregório Varvakis

\section{Introdução}

A informação é um recurso frequentemente utilizado na implementação, avaliação e controle de bens e serviços em organizações de diversos segmentos. (BRITO; ESCRIVÃO FILHO, 2011). Nesse sentido, Faria e Gadelha (2016) concordam que o acesso à informação de qualidade para a percepção dos ambientes organizacionais contribui para o desenvolvimento efetivo do Planejamento Estratégico (PE).

Embora sejam caracterizadas como instituições sem fins lucrativos, as Bibliotecas Universitárias (BU) também precisam se planejar estrategicamente, pois estão inseridas em um contexto competitivo, na medida em que representam um quesito importante para a avaliação das Instituições de Ensino Superior (IES), e, por isso, buscam constantemente por maior visibilidade e investimentos.

Gianesi e Corrêa (2009) concordam que os rumos de uma organização são definidos a partir da sua estratégia corporativa e competitiva, que, por sua vez, exerce influência sobre a estratégia funcional, situada no nível de operações. Nesse aspecto, as BU atuam no nível funcional, pois são consideradas unidades suplementares das universidades, também oferecem suporte informacional às atividades de ensino, pesquisa e extensão, e, por isso, devem obedecer aos critérios competitivos priorizados e aos planos de ação definidos pelas IES. (GOMES; BARBOSA, 2003; LION; GOMES, 2013).

O PE implica a adoção de uma metodologia que se orienta pela análise e pelo reconhecimento dos ambientes interno e externo, ou seja, para que a organização garanta sua permanência no mercado, torna-se necessária uma maior interação com seus diversos públicos. (HITT; IRELAND; HOSKISSON, 2011). Desse modo, estudos indicam a análise dos ambientes organizacionais como uma das principais ferramentas para a tomada de decisão e definição de planos de ação (VASCONCELLOS FILHO, 1979; ALMEIDA, 1997; HITT; IRELAND; HOSKISSON, 2011; CERTO; PETER, 2010), pois, por meio da análise ambiental, é possível visualizar ameaças, debilidades e oportunidades capazes de interferir, ou até mesmo alterar a estratégia organizacional. 


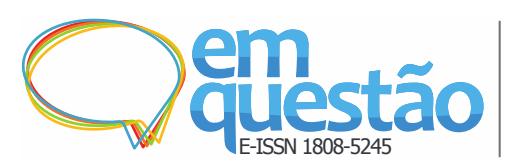

Uso de fontes de informação no monitoramento dos ambientes oraganizacionais: subsídios para o planejamento estratégico em bibliotecas universitárias brasileiras

Everton Rodrigues Barbosa, Raquel Alexandre de Lira, Angel Freddy Godoy Viera e Gregório Varvakis

Com o volume de informações publicadas e acessíveis por meio da web, a possibilidade de coletar conteúdo de qualidade para subsidiar decisões estratégicas no âmbito organizacional torna-se um desafio. (BRITO; ESCRIVÃO FILHO, 2011). Assim, a seleção e o uso de recursos de informação apropriados para a elaboração do PE contribuem para que as BU conheçam a realidade institucional e o ambiente em que estão inseridas, de modo a estabelecer ações estratégicas para a promoção de serviços de informação.

Nesse contexto, Barbosa (2006) afirma que as fontes de informação exercem papel fundamental no gerenciamento de informações estratégicas. A aquisição de informação é considerada uma das etapas da gestão da informação e elemento capaz de subsidiar o PE a partir das fontes formais e informais, pessoais ou impessoais:

A aquisição da informação equilibra duas demandas opostas. Por um lado, as necessidades de informação da organização são muitas, refletindo a extensão e a diversidade de suas preocupações com os acontecimentos e mudanças do ambiente externo. Por outro lado, a atenção e a capacidade cognitiva do homem são limitadas, o que obriga a organização a selecionar as mensagens a que dará atenção. A primeira demanda sugere que as fontes usadas para monitorar o ambiente sejam suficientemente numerosas e variadas para refletir todo o espectro de interesses da organização [...]. A seleção e o uso das fontes de informação têm de ser planejados e continuamente monitorados e avaliados, como qualquer outro recurso vital para a organização. (CHOO, 2011, p. 407).

Dada a pertinência de coletar informação útil para a tomada de decisão, as fontes de informação podem ser aplicadas ao monitoramento dos ambientes organizacionais. O uso efetivo das informações estratégicas condiciona-se aos interesses das instituições, havendo, portanto, a necessidade de identificar, avaliar e selecionar os recursos informacionais disponíveis continuamente.

Diante disso, o estudo tem como objetivo propor uma categorização das fontes de informação para o monitoramento dos ambientes organizacionais das BU, considerando que tais recursos oferecem subsídios para a elaboração do PE.

Parte do pressuposto de que os relatos de experiência e estudos de caso apresentados em anais de congressos e periódicos nacionais da área da Ciência 


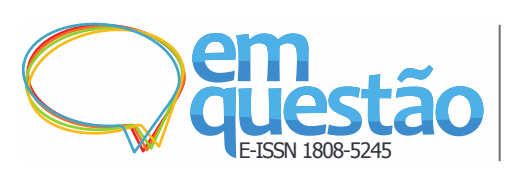

Uso de fontes de informação no monitoramento dos ambientes oraganizacionais: subsídios para o planejamento estratégico em bibliotecas universitárias brasileiras

Everton Rodrigues Barbosa, Raquel Alexandre de Lira, Angel Freddy Godoy Viera e Gregório Varvakis

da Informação indicam quais variáveis ambientais devem ser consideradas, e quais recursos informacionais devem ser utilizados para apoiar o planejamento.

\section{Planejamento estratégico em bibliotecas universitárias: um olhar sobre o monitoramento dos ambientes organizacionais}

Para Matus (2016), planejar significa pensar sistematicamente antes de agir. O planejamento é uma ferramenta para pensar e criar o futuro, considerado "[...] a mão visível, que explora as possibilidades em circunstâncias nas quais a mão invisível é incompetente ou não existe.” (MATUS, 2016, p. 14). Isto é, ou sabemos como planejar, ou somos forçados a improvisar.

Di Foggi, Coletta e Cristianini (2010) afirmam que "[...] o planejamento estratégico de uma biblioteca segue as mesmas normas e conceitos de uma empresa." (DI FOGGI; COLETTA, CRISTIANINI, 2010, p. 2). Embora não visem lucro econômico, as bibliotecas administram os recursos da instituição dedicados à gestão de coleções e serviços de informação e a aquisição de materiais informacionais e mobiliários, entre outros. Corroborando essa afirmação, Carvalho (2008) acrescenta que os gestores precisam estar conscientes de que as bibliotecas não são imutáveis nem independentes, por isso, considera que "[...] é melhor lidar com algo que já havia sido planejado do que com uma situação súbita e inesperada." (CARVALHO, 2008, p. 2).

Lira (2015) reitera que a gestão da BU necessita concentrar seus esforços para encarar os desafios de um mundo em constante mutação, tornando-se necessária a adoção de modelos de administração que priorizem a atuação participativa dos atores sociais envolvidos no processo de gestão.

O desenvolvimento tecnológico, como consequência do surgimento do que se convencionou denominar de Sociedade da Informação, abriu um novo leque de oportunidades para as bibliotecas universitárias. (OLIVEIRA, 2004). França e Carvalho (2014) reiteram que as tecnologias digitais apresentam-se como instrumentos auxiliares para a gestão de bibliotecas, permitindo estabelecer, de maneira dinâmica, suas diretrizes e definir as políticas e metas a alcançar. 


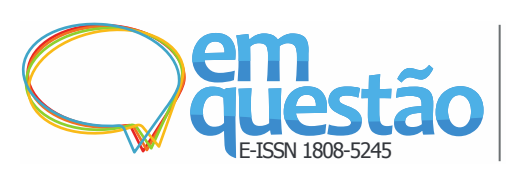

Uso de fontes de informação no monitoramento dos ambientes oraganizacionais: subsídios para o planejamento estratégico em bibliotecas universitárias brasileiras

Everton Rodrigues Barbosa, Raquel Alexandre de Lira, Angel Freddy Godoy Viera e Gregório Varvakis

Considerando os problemas de investimentos enfrentados pelas BU brasileiras, a importância da atuação participativa e as mudanças contínuas dos seus cenários de atuação, as bibliotecas adotaram o PE como uma importante ferramenta para guiar suas decisões. Entre as BU, se destacam a da Universidade de São Paulo (USP) e da Universidade Estadual de Campinas (UNICAMP), como instituições que se preocupam em formular, documentar e disponibilizar seus planos estratégicos. E assim, reúnem as melhores práticas, servindo de modelo para demais instituições (LIRA, 2015).

\subsection{Bibliotecas universitárias}

As BU não podem ser caracterizadas como elementos isolados, uma vez que coexistem como subsistema da universidade, em função da qual seus propósitos são estabelecidos. São organizações prestadoras de serviços e, pela sua origem, natureza e vocação funcional, estão intimamente relacionadas com: a difusão e partilha do saber; a investigação; a cultura; o conhecimento; a aprendizagem e os processos de socialização, conformação e transformação dos sistemas ideológicos da humanidade (CARVALHO, 2016).

Assim, as BU deixaram de ser consideradas meros depósitos ordenados de documentos, e passaram a ser consideradas organizações ou comunidades de atores, cujas práticas interativas asseguram a disseminação e a produção do conhecimento (WATSON, 2010). Tendem a converter-se em um espaço redimensionado, em uma plataforma integradora de conhecimento válido e adaptada a um modelo de ensino que, tendencialmente, deixou de estar centrado no papel do professor para estar fundado na autoaprendizagem (PEREZ RODRIGUEZ; MILANES GUISADO, 2008).

O Brasil não possui estatísticas a respeito dos diferentes tipos de bibliotecas existentes, porém, é possível calcular o número de bibliotecas em instituições de nível superior, tendo em vista que a autorização para o funcionamento destas depende, dentre outros fatores, da existência da biblioteca (CENDÓN et al. 2005). Diante do exposto, é possível mensurar a importância das bibliotecas no contexto universitário. 


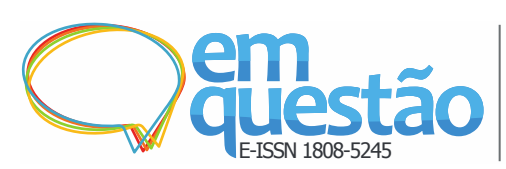

Uso de fontes de informação no monitoramento dos ambientes oraganizacionais: subsídios para o planejamento estratégico em bibliotecas universitárias brasileiras

Everton Rodrigues Barbosa, Raquel Alexandre de Lira, Angel Freddy Godoy Viera e Gregório Varvakis

Conforme os resultados do Censo da Educação Superior do Instituto Nacional de Estudos e Pesquisas Educacionais Anísio Teixeira (2017), existem no país, pelo menos, 2.407 bibliotecas nas Instituições de Ensino Superior; das quais: 107 nas instituições federais; 123 nas estaduais; 66 nas municipais e 2111 nas privadas. Ante ao exposto, é possível inferir a importância das bibliotecas, nas diversas instituições, como suporte ao tripé: ensino, pesquisa e extensão.

De acordo com Lubisco (2014), as atividades das BU tradicionalmente se desenvolvem por meio de serviços aos usuários, serviços administrativos e serviços técnicos. Porém, Shoid e Kassim (2013) indicam que as mudanças constantes nos ambientes organizacional, tecnológico e informacional geram mudanças de comportamentos nos usuários e trazem novos desafios para as BU.

\subsection{Os ambientes organizacionais das bibliotecas universitárias}

Para Almeida (2011), o planejamento implica em identificar os pontos fortes, fracos, oportunidades e ameaças, de modo que os fortes sejam maximizados, as oportunidades sejam aproveitadas, os fracos eliminados e as ameaças neutralizadas. O PE é um direcionamento para a Biblioteca Universitária em relação ao seu ambiente de atuação, conforme suas reais potencialidades. (LIRA, 2015).

Certo e Peter (2010) afirmam que a análise do ambiente permite identificar as oportunidades e os riscos que podem comprometer o alcance dos objetivos ou metas organizacionais. As variáveis que definem os ambientes organizacionais se apresentam na literatura de maneira diversificada e estão condicionadas às características de um determinado segmento.

De modo geral, as abordagens de segmentos e variáveis ambientais foram discutidas por Almeida (1997), e são apresentadas no quadro 1 em conjunto com algumas das abordagens de estudos mais recentes. 
Uso de fontes de informação no monitoramento dos ambientes oraganizacionais: subsídios para o planejamento estratégico em bibliotecas universitárias brasileiras

Everton Rodrigues Barbosa, Raquel Alexandre de Lira, Angel Freddy Godoy Viera e Gregório Varvakis

Quadro 1 - Categorias de segmentos e variáveis ambientais abordadas nos estudos sobre o monitoramento de ambientes organizacionais

\begin{tabular}{|c|c|c|}
\hline Autores & Segmento ambiental & Variáveis/ Características \\
\hline \multirow{3}{*}{$\begin{array}{l}\text { Glueck } \\
(1976)\end{array}$} & $\begin{array}{l}\text { Fatores ambientais } \\
\text { genéricos }\end{array}$ & $\begin{array}{l}\text { Mudanças sociais, econômicas, governamentais, } \\
\text { políticas, populacionais e comunitárias; grupos } \\
\text { consumidores. }\end{array}$ \\
\hline & $\begin{array}{l}\text { Fatores } \\
\text { fornecedores }\end{array}$ & $\begin{array}{l}\text { Mudanças de preço e fornecedores de matéria-prima; } \\
\text { descobertas tecnológicas que afetam o sistema de } \\
\text { entrega de produto ou serviço. }\end{array}$ \\
\hline & Fatores de mercado & $\begin{array}{l}\text { Novos produtos ou serviços; mudanças na estrutura } \\
\text { de preços e demandas dos consumidores; novos } \\
\text { competidores; mudanças nos ciclos de vida dos } \\
\text { produtos. }\end{array}$ \\
\hline \multirow{3}{*}{$\begin{array}{l}\text { Vasconcellos } \\
\text { Filho (1979) }\end{array}$} & Macro ambientais & $\begin{array}{l}\text { Variáveis econômicas, } \begin{array}{c}\text { sociais, } \\
\text { demográficas, políticas, tecnológicas, legais e } \\
\text { ecológicas. }\end{array} \\
\end{array}$ \\
\hline & Ambiente operacional & $\begin{array}{l}\text { Grupos de pessoas, entidades, empresas e órgãos do } \\
\text { governo que mantêm um processo de intercâmbio } \\
\text { com a organização, através de relacionamentos } \\
\text { diversos (consumo, fornecimento, financiamento, } \\
\text { apoio, antagonismo etc.). }\end{array}$ \\
\hline & Ambiente Interno & $\begin{array}{l}\text { Públicos relevantes internos e elementos da oferta } \\
\text { expandida da organização. }\end{array}$ \\
\hline \multirow{3}{*}{$\begin{array}{l}\text { Miller } \\
(1987)\end{array}$} & Dinamismo & $\begin{array}{l}\text { Gosto dos consumidores, tecnologia de produtos e } \\
\text { serviços, modos de competição. }\end{array}$ \\
\hline & Heterogeneidade & $\begin{array}{l}\text { Gosto de consumidores, linhas de produtos, canais de } \\
\text { distribuição. }\end{array}$ \\
\hline & Hostilidade & $\begin{array}{l}\text { Competitividade, escassez de mão de obra e matéria } \\
\text { prima, redução de mercado. }\end{array}$ \\
\hline \multirow{4}{*}{$\begin{array}{l}\text { Narayanan e } \\
\text { Fahey } \\
(1994)\end{array}$} & Nível de operações & Clientes, fornecedores e competidores. \\
\hline & Nível da indústria & Dinâmicas e estruturas do ramo de atividade. \\
\hline & $\begin{array}{l}\text { Nível do ambiente de } \\
\text { relevância }\end{array}$ & Variáveis relevantes para o propósito de análise. \\
\hline & $\begin{array}{l}\text { Nível do macro } \\
\text { ambiente }\end{array}$ & Social, político, econômico e tecnológico. \\
\hline \multirow{3}{*}{$\begin{array}{l}\text { Davenport } \\
\text { (1998) }\end{array}$} & Ambiente externo & $\begin{array}{l}\text { Mercados de negócios; Mercados de informação; } \\
\text { Mercados tecnológicos. }\end{array}$ \\
\hline & $\begin{array}{l}\text { Ambiente } \\
\text { organizacional }\end{array}$ & $\begin{array}{l}\text { Situação dos negócios; Investimentos em tecnologias; } \\
\text { Distribuição física. }\end{array}$ \\
\hline & $\begin{array}{l}\text { Ambiente } \\
\text { informacional }\end{array}$ & $\begin{array}{l}\text { Equipe; Estratégia; Cultura/comportamento; Processo } \\
\text { de administração; Arquitetura da informação; Política } \\
\text { de informação. }\end{array}$ \\
\hline \multirow{3}{*}{$\begin{array}{l}\text { Certo e Peter } \\
(2010)\end{array}$} & Ambiente geral & $\begin{array}{l}\text { Aspectos econômicos, sociais, culturais, } \\
\text { demográficos, políticos, tecnológicos e legais. }\end{array}$ \\
\hline & $\begin{array}{l}\text { Ambiente } \\
\text { organizacional }\end{array}$ & $\begin{array}{l}\text { Pessoas, grupos de pessoas, entidades, empresas e } \\
\text { órgãos do governo. }\end{array}$ \\
\hline & Ambiente interno & $\begin{array}{l}\text { Redes de comunicação, produção, marketing e } \\
\text { recursos humanos. }\end{array}$ \\
\hline \multirow{2}{*}{$\begin{array}{l}\text { Chiavenato } \\
(2011)\end{array}$} & Macroambiente & $\begin{array}{l}\text { Demográfico, sociocultural, tecnológico, recursos } \\
\text { globais, político/legal e econômico. }\end{array}$ \\
\hline & Microambiente & $\begin{array}{l}\text { Concorrentes, clientes, fornecedores e agentes } \\
\text { reguladores. }\end{array}$ \\
\hline
\end{tabular}

Fonte: Elaborado pelos autores. 


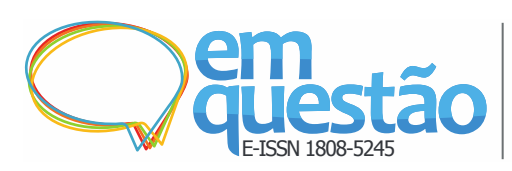

Uso de fontes de informação no monitoramento dos ambientes oraganizacionais: subsídios para o planejamento estratégico em bibliotecas universitárias brasileiras

Everton Rodrigues Barbosa, Raquel Alexandre de Lira, Angel Freddy Godoy Viera e Gregório Varvakis

Por meio da pesquisa nas bases de dados nacionais, pode-se perceber que a literatura da área da Ciência da Informação e Biblioteconomia não apresenta uma abordagem específica e amplamente difundida sobre a análise dos ambientes organizacionais das bibliotecas acadêmicas brasileiras.

Nessa perspectiva, algumas variáveis ambientais apresentadas no quadro 1 podem ser aplicadas ao contexto das BU. A semelhança entre as abordagens nos permite reuni-las em três grandes ambientes distintos:

a) ambiente geral - externo à biblioteca onde se acham os componentes de nível macro, sobre os quais as BU não têm controle, como as variáveis econômicas, sociais, culturais, demográficas, políticas, tecnológicas, legais e ecológicas que influenciam o funcionamento das IES;

b) ambiente organizacional ou operacional - também externo às BU, composto por setores relevantes com os quais as BU mantêm vários tipos de relacionamentos, como pessoas, grupos de pessoas (usuários), entidades, empresas e órgãos do governo, ou seja, públicos que normalmente têm implicações específicas e imediatas na organização;

c) ambiente interno - formado pelos públicos relevantes internos, suscetíveis ao controle imediato da administração, composto pelas redes de comunicação, produção, marketing e recursos humanos.

Para cada cenário de atuação das BU brasileiras, existe um tipo de recurso ou fonte de informação que irá contribuir com a análise das variáveis ambientais necessárias para o estabelecimento de ações estratégicas.

Considerando o PE em BU uma necessidade e, diante da ausência de publicações sobre fontes de informação para sua implementação no contexto das bibliotecas acadêmicas, realizou-se, por meio da pesquisa bibliográfica, um levantamento dos recursos informacionais capazes de auxiliar os bibliotecários gestores na elaboração de ações estratégicas em BU. 


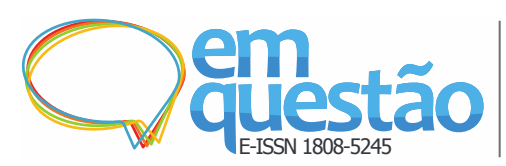

Uso de fontes de informação no monitoramento dos ambientes oraganizacionais: subsídios para o planejamento estratégico em bibliotecas universitárias brasileiras

Everton Rodrigues Barbosa, Raquel Alexandre de Lira, Angel Freddy Godoy Viera e Gregório Varvakis

\section{Percurso metodológico}

A pesquisa caracteriza-se como exploratória descritiva, com elementos de pesquisa qualitativa e quantitativa. O levantamento das fontes de informação foi realizado a partir da análise das publicações científicas nacionais sobre o PE em BU.

Para isso, a pesquisa - realizada entre agosto de 2017 e fevereiro de 2018 - se concentrou no levantamento de relatos de experiência e estudos de caso contidos nos artigos dos anais eletrônicos dos seguintes eventos: Seminário Nacional de Bibliotecas Universitárias (SNBU), Congresso Brasileiro de Biblioteconomia, Documentação e Ciência da Informação (CBBD) e Encontro Nacional de Pesquisa em Ciência da Informação (ENANCIB).

Para o levantamento de artigos publicados em periódicos, utilizou-se a pesquisa na Base de Dados em Ciência da Informação (BRAPCI). Os termos de busca "Planejamento estratégico", "Bibliotecas Universitárias" e "Gestão de Bibliotecas" foram aplicados tanto na BRAPCI quanto nos anais eletrônicos.

Para a recuperação dos artigos, os termos de busca foram combinados utilizando o operador booleano " $A N D$ " nas bases de dados que disponibilizavam mecanismos avançados de busca. Para as bases que não ofereciam a opção de busca avançada, a alternativa encontrada foi realizar a busca termo a termo.

Foram selecionados relatos de experiência e estudos de caso publicados entre 2009 e 2017, resultando em um total de 33 artigos, nos quais se procurou, por meio da leitura dos textos, identificar as fontes de informação utilizadas para fundamentar as discussões sobre o $\mathrm{PE}$ em BU, e, por meio da análise de citações, verificar os tipos de fontes de informação mais utilizados e os autores mais mencionados nessas obras.

4 Fontes de informação para o planejamento estratégico de bibliotecas universitárias brasileiras

Nos 33 artigos analisados, constam 473 citações utilizadas para fundamentar os estudos de caso ou relatos de experiência selecionados. Em relação ao período 


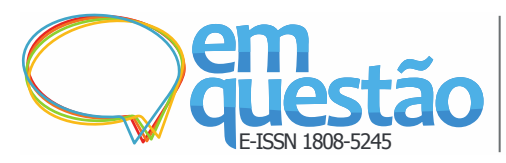

Uso de fontes de informação no monitoramento dos ambientes oraganizacionais: subsídios para o planejamento estratégico em bibliotecas universitárias brasileiras

Everton Rodrigues Barbosa, Raquel Alexandre de Lira, Angel Freddy Godoy Viera e Gregório Varvakis

cronológico mais expressivo das publicações, os anos de 2013 e 2014 registraram o ápice da produção.

Gráfico 1 - Frequência anual de publicações sobre o Planejamento Estratégico em Bibliotecas Universitárias

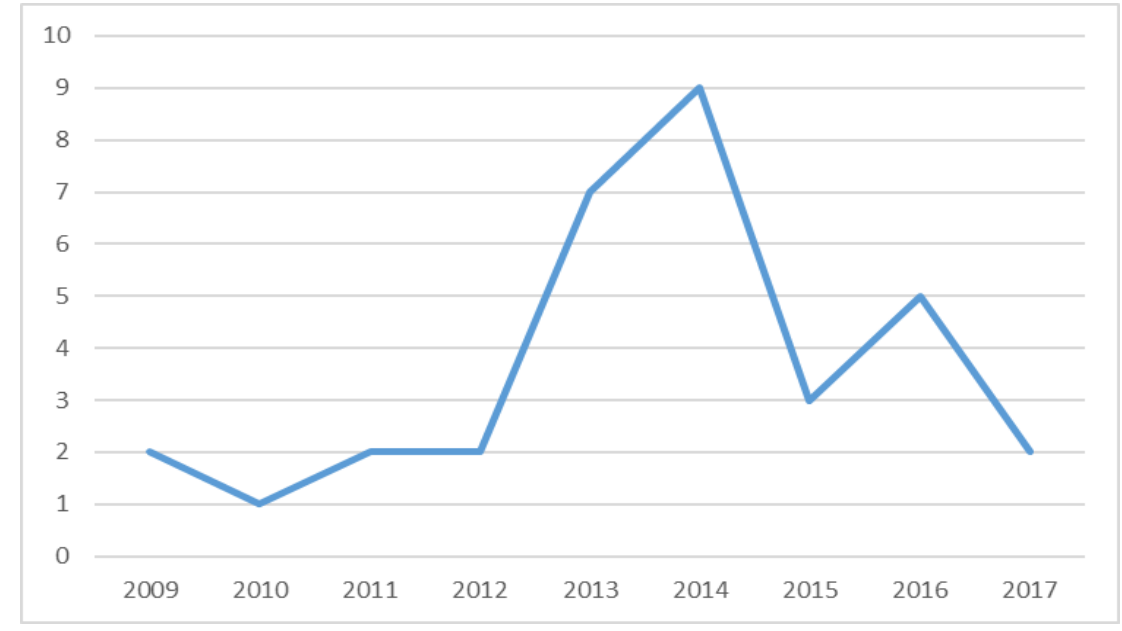

Fonte: Dados da pesquisa.

O levantamento revelou que o tipo de fonte de informação mais utilizado é o livro, representando 39,75\% das fontes, seguido dos artigos em periódicos e em anais de eventos. Analisando a quantidade de artigos, destacaram-se como principais eventos: o SNBU $(n=30)$, o CBBD $(n=9)$ e o ENANCIB $(n=3)$.

Tabela 1 - Tipos de fontes de informação mais utilizados nas publicações sobre Planejamento Estratégico em Bibliotecas Universitárias

\begin{tabular}{ccc}
\hline Fontes de Informação & Frequência & Porcentagem \\
\hline Livros & 188 & $39,75 \%$ \\
\hline Artigos em periódicos & 115 & $24,31 \%$ \\
Artigos em anais de eventos & 56 & $11,84 \%$ \\
Dissertações & 25 & $5,29 \%$ \\
Documentos de órgãos governamentais & 24 & $5,07 \%$ \\
Documentos/páginas web & 22 & $4,65 \%$ \\
Documentos de IES & 14 & $2,96 \%$ \\
Teses & 10 & $2,11 \%$ \\
Legislação & 9 & $1,90 \%$ \\
Trabalhos de Conclusão de Curso & 6 & $1,27 \%$ \\
Normas Técnicas & 4 & $0,85 \%$ \\
\hline Total & 473 & $100 \%$ \\
\hline Fonte: Dados da pesquisa. &
\end{tabular}


Os 115 artigos de periódicos citados estão distribuídos em 60 títulos de periódicos diferentes, destacando-se as publicações com mais de cinco artigos: Ciência da Informação (n=17), Perspectivas em Ciência da Informação (n=8) e DataGramaZero $(n=6)$, as quais representam os periódicos mais utilizados.

Entre os 24 documentos de órgãos governamentais citados, estão: FINEP $(n=2)$; CAPES $(n=1)$; manuais e diretrizes do MEC $(n=13)$; documentos da Presidência $(n=1)$; leis e decretos $(n=9)$, sendo que nos três últimos constam as diretrizes do órgão para a avaliação das IES. Os documentos das IES correspondem aos relatórios de gestão, planos de ação, resoluções internas e informações genéricas sobre as IES, todos disponíveis eletronicamente através de suas páginas institucionais na web.

Em relação aos autores mais citados, as publicações governamentais foram as que mais se destacaram, especialmente aquelas que contêm resoluções, manuais, diretrizes e legislação brasileira destinada à regularização e avaliação das IES. A Tabela 2 expõe a utilização de obras de autores da área de administração, como Chiavenato (edições entre 1994-2014) e Oliveira (edições entre 1997-2011). Os demais autores se destacam pelos estudos na área de planejamento, gestão de bibliotecas e gestão da qualidade dos serviços de informação.

Tabela 2 - Autores mais citados nas publicações sobre Planejamento Estratégico em Bibliotecas Universitárias

\begin{tabular}{cc}
\hline Autores & Número de citações \\
\hline BRASIL. & 27 \\
CHIAVENATO, Idalberto. & 16 \\
MACIEL, Alba Costa; MENDONÇA, Marília & 8 \\
Alvarenga Rocha. & 7 \\
BARBALHO, Célia Regina Simonetti. & 7 \\
VERGUEIRO, Waldomiro. & 6 \\
ALMEIDA, Maria Christina Barbosa. & 6 \\
CUNHA, Murilo Bastos da. & 5 \\
\hline OLIVEIRA, Djalma de P. Rebouças de. & \\
\hline
\end{tabular}

Fonte: Dados da pesquisa. 
Uso de fontes de informação no monitoramento dos ambientes oraganizacionais: subsídios para $\mathrm{o}$ planejamento estratégico em bibliotecas universitárias brasileiras

Everton Rodrigues Barbosa, Raquel Alexandre de Lira, Angel Freddy Godoy Viera e Gregório Varvakis

As obras mais mencionadas nos trabalhos analisados foram os livros de Almeida (edições entre 2000-2005), que simbolizam o referencial teórico mais utilizado sobre o planejamento estratégico de bibliotecas e serviços de informação; e Oliveira (edições entre 1997-2011), que discorre sobre conceitos, metodologias e práticas voltadas para o planejamento estratégico. Entre as publicações de periódicos, destacou-se um estudo de Cunha (2000) como o artigo mais citado. ${ }^{1}$

Quadro 2 - Obras mais citadas nas publicações sobre Planejamento Estratégico em Bibliotecas Universitárias

\begin{tabular}{|c|c|c|c|}
\hline Autor & Título/Dados da publicação & $\begin{array}{c}\text { Tipo de } \\
\text { documento }\end{array}$ & $\begin{array}{l}\text { Quantidade } \\
\text { de citações }\end{array}$ \\
\hline $\begin{array}{l}\text { ALMEIDA, } \\
\text { Maria Christina } \\
\text { Barbosa }\end{array}$ & $\begin{array}{l}\text { Planejamento de bibliotecas e serviços de } \\
\text { informação. Brasília, DF: Briquet de Lemos, } \\
\text { 2000-2005. }\end{array}$ & Livro & 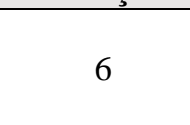 \\
\hline $\begin{array}{l}\text { OLIVEIRA, } \\
\text { Djalma de P. } \\
\text { Rebouças de. }\end{array}$ & $\begin{array}{c}\text { Planejamento Estratégico: Conceitos, } \\
\text { Metodologia, Práticas. São Paulo: Atlas, } \\
\text { 1997-2011. }\end{array}$ & Livro & 5 \\
\hline $\begin{array}{l}\text { CHIAVENATO, } \\
\text { Idalberto. }\end{array}$ & $\begin{array}{c}\text { Introdução à teoria geral da administração. } \\
\text { São Paulo: Makron Books, 1994-2014. }\end{array}$ & Livro & 5 \\
\hline $\begin{array}{l}\text { CUNHA, Murilo } \\
\text { Bastos da. }\end{array}$ & $\begin{array}{c}\text { Construindo o futuro: a biblioteca } \\
\text { universitária brasileira em 2010. Ciência da } \\
\text { informação, Brasília, DF, v. 29, n.1, p. 71-89, } \\
\text { jan./abr., 2000. }\end{array}$ & $\begin{array}{l}\text { Artigo em } \\
\text { periódico }\end{array}$ & 4 \\
\hline $\begin{array}{c}\text { MACIEL, Alba } \\
\text { Costa; } \\
\text { MENDONÇA, } \\
\text { Marília } \\
\text { Alvarenga Rocha. }\end{array}$ & $\begin{array}{l}\text { Bibliotecas como organizações. Rio de } \\
\text { Janeiro: Interciência, 2000-2006. }\end{array}$ & Livro & 4 \\
\hline $\begin{array}{c}\text { MACIEL, Alba } \\
\text { Costa; } \\
\text { MENDONÇA, } \\
\text { Marília } \\
\text { Alvarenga Rocha. }\end{array}$ & $\begin{array}{l}\text { A função gerencial na biblioteca universitária. } \\
\text { In: SEMINÁRIO NACIONAL DE } \\
\text { BIBLIOTECAS UNIVERSITÁRIAS, 11., } \\
\text { 2000. Anais... Florianópolis, 2000. }\end{array}$ & $\begin{array}{l}\text { Artigo em } \\
\text { anais de } \\
\text { evento }\end{array}$ & 3 \\
\hline $\begin{array}{l}\text { BARBALHO, } \\
\text { Célia Regina } \\
\text { Simonetti. }\end{array}$ & $\begin{array}{l}\text { Planejamento estratégico: uma análise } \\
\text { metodológica. Informação \& Informação, } \\
\text { Londrina, v. 2, n. 1, p. 29-44, jan. /jun. } 1997 .\end{array}$ & $\begin{array}{l}\text { Artigo de } \\
\text { periódico }\end{array}$ & 3 \\
\hline $\begin{array}{l}\text { BRASIL. } \\
\text { Ministério da } \\
\text { Educação. }\end{array}$ & $\begin{array}{l}\text { Instrumento de Avaliação Institucional } \\
\text { Externa. Brasília: Ministério da Educação, } \\
\text { Instituto Nacional de Estudos e Pesquisas } \\
\text { Educacionais Anísio Teixeira (INEP), } 2010 .\end{array}$ & $\begin{array}{c}\text { Document } \\
\text { o de órgão } \\
\text { govername } \\
\text { ntal }\end{array}$ & 3 \\
\hline $\begin{array}{l}\text { VERGUEIRO, } \\
\text { Waldomiro. }\end{array}$ & $\begin{array}{c}\text { Qualidade em serviços de informação. São } \\
\text { Paulo: Arte e Ciência, } 2002 .\end{array}$ & Livro & 3 \\
\hline
\end{tabular}

Fonte: Dados da pesquisa.

Ao analisar os estudos, percebeu-se um direcionamento ao uso de fontes pessoais e impessoais destinadas à compreensão dos diversos segmentos ambientais das BU. 


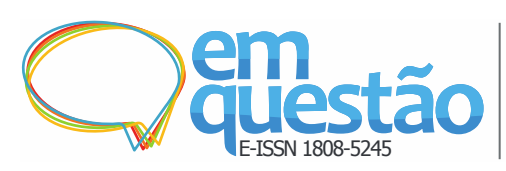

Uso de fontes de informação no monitoramento dos ambientes oraganizacionais: subsídios para o planejamento estratégico em bibliotecas universitárias brasileiras

Everton Rodrigues Barbosa, Raquel Alexandre de Lira, Angel Freddy Godoy Viera e Gregório Varvakis

\section{Uso das fontes de informação}

Conhecidas as tipologias, obras e autores mais mencionados, vale ressaltar como esses recursos informacionais são abordados na literatura nacional. Não se pretende discutir exaustivamente os temas pontuados, mas sim destacar a importância de cada tópico para a elaboração e implementação de ações estratégicas no âmbito das BU brasileiras, de acordo com os estudos analisados.

\subsection{Legislação, diretrizes, normas e manuais técnicos}

As BU, como unidades suplementares das IES inseridas em um contexto macro, necessitam atender aos valores, missão e visão das instituições nas quais estão inseridas. Nesse contexto, suas estratégias precisam obedecer tanto ao conjunto de diretrizes internas, explicitadas nos Planos de Desenvolvimento Institucional (PDI), como às externas, no que se refere à legislação que regula e avalia a educação superior nacional, estabelecida por órgãos governamentais.

No que concerne às diretrizes para implantação e organização de BU no Brasil, o Ministério da Educação (MEC) - por meio dos instrumentos dispostos nas portarias no. 1.382 e 1.383 , de 31 de outubro de 2017 - fixa os procedimentos de avaliação externa do Sistema Nacional de Avaliação da Educação Superior (SINAES), incluindo a estrutura física e a pertinência das bibliografias básicas, complementares e periódicos (BRASIL, 2017a; 2017b).

A avaliação da educação superior firmou-se com a Lei no. 9.394, de 20 de dezembro de 1996, que estabeleceu as Diretrizes de Base da Educação Nacional (LDB) (BRASIL, 1996). Em 2002, o MEC publicou o Manual de verificação in loco das condições institucionais, que, conforme os trabalhos analisados, representa uma das fontes mais utilizadas pelas bibliotecas para observar os quesitos de avaliação do MEC (BRASIL, 2002).

Porém, atualmente, existem os instrumentos de avaliação institucional externa, que apontam os principais indicadores para a avaliação dos cursos de graduação presenciais e a distância oferecidos pelas IES, incluindo os critérios de análise para os indicadores de infraestrutura e plano de atualização dos acervos das BU (BRASIL, 2017c). 


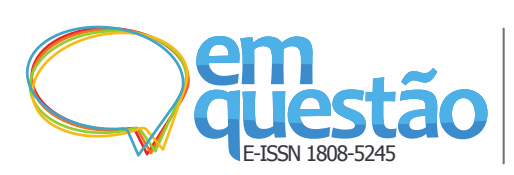

Uso de fontes de informação no monitoramento dos ambientes oraganizacionais: subsídios para o planejamento estratégico em bibliotecas universitárias brasileiras

Everton Rodrigues Barbosa, Raquel Alexandre de Lira, Angel Freddy Godoy Viera e Gregório Varvakis

Os instrumentos supracitados dispõem sobre a estrutura física das IES, especialmente no que tange às atividades de ensino, pesquisa, biblioteca, recursos de informação e comunicação. Em relação às bibliotecas, consta no documento que são avaliadas suas estruturas físicas e seus acervos, observandose as seguintes condições:

a) acessibilidade física, disponibilidade de estações individuais e coletivas para estudos e recursos tecnológicos para consulta, guarda, empréstimo e organização do acervo, condições para o atendimento educacional especializado e recursos inovadores;

b) políticas institucionais de aquisição, expansão e atualização do acervo conforme descritos nos PDI, considerando a alocação de recursos e as ações corretivas associadas ao acompanhamento e avaliação do acervo pela comunidade (BRASIL, 2017c).

Esses critérios são fundamentais para a implantação das BU, uma vez que exercem influência sobre a qualidade das atividades das IES. (LUBISCO, 2014). Embora sejam indutores do PE, os critérios apontados nos instrumentos de avaliação não se aprofundam em como as BU necessitam agir, ou seja, seus desempenhos estão condicionados aos esforços das unidades em cumprir com as exigências mínimas do MEC.

Diante das diversas diretrizes, recomenda-se observar a atualização dos instrumentos de avaliação do MEC, pois podem sofrer alterações, principalmente quando ocorre a troca de governos. Para além das alterações, os novos instrumentos não suprimem a importância dos instrumentos anteriores.

Entre os instrumentos norteadores, que orientam e oferecem diretrizes ao desenvolvimento de atividades no âmbito interno das IES, estão os Planos de Desenvolvimento Institucional (PDI), compreendidos como:

[...] o documento que identifica a Instituição de Ensino Superior (IES), no que diz respeito à sua filosofia de trabalho, à missão a que se propõe, às diretrizes pedagógicas que orientam suas ações, à sua estrutura organizacional e às atividades acadêmicas que desenvolve e/ou que pretende desenvolver. (BRASIL, 2007). 


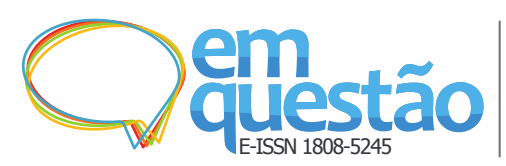

Uso de fontes de informação no monitoramento dos ambientes oraganizacionais: subsídios para o planejamento estratégico em bibliotecas universitárias brasileiras

Everton Rodrigues Barbosa, Raquel Alexandre de Lira, Angel Freddy Godoy Viera e Gregório Varvakis

O PDI oferece informações relevantes para a compreensão das ações estratégicas das universidades, dispõe sobre o papel de cada unidade suplementar da instituição acadêmica, inclusive da BU, cuja missão é oferecer suporte informacional às atividades de ensino, pesquisa e extensão.

Do mesmo modo, Cobbe (2013) destaca a importância de criar equipes diversificadas de trabalho, compostas por gestores de unidades, coordenadores de curso, professores e técnicos administrativos, que, por meio de ferramentas de trabalho, possam coletar e analisar indicadores de desempenho para a solução de problemas e avaliação constante dos objetivos organizacionais.

Segundo Cobbe e colaboradores (2015), para que possam atender às exigências do MEC, as IES necessitam incorporar mudanças no ambiente a partir da implantação de duas medidas estruturantes:

a) construção de seus PDI, alicerçado nos indicadores de qualidade do MEC, permitindo a avaliação sistemática e periódica das metas;

b) difusão das metas em todas as instâncias da IES, bem como a conscientização dos seus colaboradores frente ao progresso da instituição.

Dada à necessidade de avaliar a qualidade dos bens e produtos de informação em BU, a NBR ISO 9001:2015, que dispõe sobre os requisitos para os sistemas de gestão de qualidade, consiste em uma fonte de informação potencialmente útil para as unidades de informação, pois pode contribuir para o desempenho global das ações estratégicas definidas no âmbito das instituições.

\footnotetext{
Os benefícios potenciais para uma organização pela implementação de um sistema de gestão da qualidade baseado nesta Norma são: a) a capacidade de promover conscientemente produtos e serviços que atendam aos requisitos do cliente e aos requisitos estatutários e regulamentares aplicáveis; b) facilitar oportunidades para aumentar a satisfação do cliente; c) abordar riscos e oportunidades associados com seu contexto e objetivos; d) a capacidade de demonstrar conformidade com requisitos especificados de sistemas de gestão da qualidade. (ASSOCIAÇÃO BRASILEIRA DE NORMAS TÉCNICAS, 2015, p. 7).
}

A norma supracitada implementa a abordagem do processo que incorpora o ciclo do Plan-Do-Check-Act (PDCA) e, assim, assegura à instituição 


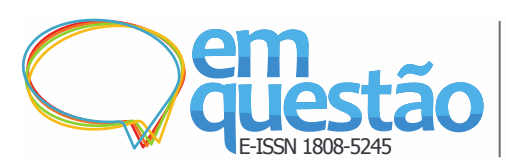

Uso de fontes de informação no monitoramento dos ambientes oraganizacionais: subsídios para o planejamento estratégico em bibliotecas universitárias brasileiras

Everton Rodrigues Barbosa, Raquel Alexandre de Lira, Angel Freddy Godoy Viera e Gregório Varvakis

utilizar recursos suficientes para o gerenciamento adequado, desvendando oportunidades e auxiliando na tomada de decisão.

Igualmente, a norma ISO 11620:2014, que trata dos indicadores de desempenho para avaliar bibliotecas, pode contribuir com o diagnóstico, bem como auxiliar para se descobrir como melhorar a alocação de recursos, pois aponta os pontos fortes e fracos, mede o uso de serviços, detecta a baixa produtividade e, assim, facilita a escolha de alternativas para combater as debilidades encontradas. (PIMENTA; COELHO JÚNIOR, 2016).

As leis, decretos, diretrizes e normas supracitadas operam como indutores do $\mathrm{PE}$, pois estabelecem normativas que guiam as BU em direção a um padrão global de decisões.

\subsection{Congressos e conferências}

Os anais de eventos são fontes de informação importantes para encontrar pesquisas mais recentes, fontes relacionadas e especialistas no campo de pesquisa e identificar melhores práticas e inovações numa área particular. (CUNHA, 2016).

No contexto das BU, os eventos destacam-se por abordar temas relacionados à tecnologia, inovação, implementação de produtos e gestão dos serviços de informação contidos nos relatos de experiência e estudos de caso publicados em seus anais de eventos.

Nesses congressos e conferências, as comunicações permitem acompanhar as tendências em pesquisas aplicadas, visualizar oportunidades de parcerias e contatos com instituições e profissionais, além de representar um recurso para a educação continuada de bibliotecários gestores no contexto brasileiro.

Ademais, acessar o conteúdo das publicações em eventos pode dar suporte a uma ferramenta de gestão denominada benchmarking, que permite medir a produtividade local, inspecionando outras bibliotecas para melhorar sua performance pela adoção ou adaptação das melhores práticas. Barbêdo (2002) afirma que "[...] a grande contribuição do Benchmarking em bibliotecas é 


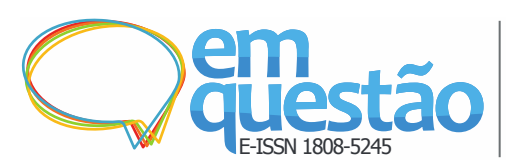

Uso de fontes de informação no monitoramento dos ambientes oraganizacionais: subsídios para o planejamento estratégico em bibliotecas universitárias brasileiras

Everton Rodrigues Barbosa, Raquel Alexandre de Lira, Angel Freddy Godoy Viera e Gregório Varvakis

descobrir o que outras bibliotecas estão fazendo que poderia ser utilizado para adicionar valor em serviços e processos." (BARBÊDO, 2002, p. 6).

O benchmarking consiste em ter, para cada atividade, um alvo ou uma fonte de comparação (referencial comparativo), ou seja, essa ferramenta identifica as boas práticas (BEHR; MORO; ESTABEL, 2010). Nesse aspecto, os anais se destacam entre as publicações como uma das principais fontes de informação utilizadas.

5.3 Diretórios de bibliotecas, entidades de classe, editoras, empresas, institutos e centros de informação no Brasil

Segundo Cunha (2016), os diretórios podem conter listas de pessoas, organizações ou assunto, endereços e nomes de dirigentes além de produtos e serviços oferecidos por instituições. Tais diretórios se configuram como fontes de informação para estabelecer parcerias, visualizar tendências e buscar oportunidades no contexto das bibliotecas universitárias.

Faria e Gadelha (2016) destacam a importância da cooperação entre bibliotecas universitárias e institutos de pesquisa, a partir da elaboração de um planejamento estratégico baseado na gestão da informação. Os autores propõem o uso de ferramentas para a análise de impacto das parcerias entre universidades e empresas na produção do conhecimento científico e tecnológico, a partir de informações extraídas das bases de dados que revelam como ocorrem as parcerias entre instituições.

No Brasil, merece destaque o Instituto Brasileiro de Informação em Ciência e Tecnologia (IBICT), por oferecer suporte tecnológico e capacitação em competência informacional para a implementação de produtos e serviços de informação em bibliotecas e centros de pesquisa. A missão do IBICT é “[...] promover a competência, o desenvolvimento de recursos e a infraestrutura de informação em ciência e tecnologia para a produção, socialização e integração do conhecimento científico e tecnológico." (INSTITUTO BRASILEIRO DE INFORMAÇÃO EM CIÊNCIA E TECNOLOGIA, 2017, doc. não paginado). 


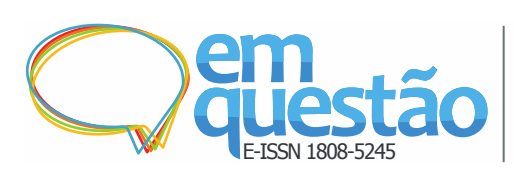

Uso de fontes de informação no monitoramento dos ambientes oraganizacionais: subsídios para o planejamento estratégico em bibliotecas universitárias brasileiras

Everton Rodrigues Barbosa, Raquel Alexandre de Lira, Angel Freddy Godoy Viera e Gregório Varvakis

O IBICT desenvolve projetos e estabelece parcerias com as BU, especialmente nas áreas de preservação digital, repositórios digitais, acesso aberto e cooperação bibliotecária. Dessa forma, caracteriza-se como uma fonte de informação governamental para a implementação de projetos e ações estratégicas voltadas para o incremento dos serviços de informação.

Igualmente, a Fundação Biblioteca Nacional (FBN), como órgão responsável pela execução da política governamental de captação, organização, preservação e difusão da produção intelectual do país, é uma instituição de renome e vanguarda, destacando-se por oferecer suporte técnico-informacional no que concerne: depósito legal; elaboração e divulgação da bibliografia corrente através dos catálogos online; serviço de intercâmbio de materiais informacionais; fonte de autoridade de autor e assunto; e ações internacionais, por meio de parcerias com bibliotecas nacionais de outros países, para troca de conhecimentos e boas práticas, promoção de pesquisas, exposições, entre outras. (FUNDAÇÃO BIBLIOTECA NACIONAL, 2017).

O portal institucional da FBN é uma fonte de pesquisa para o incremento de produtos, serviços e cooperação bibliotecária, pois consolida informações sobre a instituição, seu acervo e serviços, permitindo o acesso aos catálogos online, ao acervo digital e ao conjunto de serviços disponibilizados via internet.

No que diz respeito ao incentivo e fortalecimento do campo profissional, os diretórios das entidades de classe na web - como comissões, associações e federações - como canal de informação para divulgação de congressos, conferências, eventos e capacitação de bibliotecários. No Brasil, destacam-se a Federação Brasileira de Associações de Bibliotecários, Cientistas da Informação e Instituições (FEBAB), a Comissão Brasileira de Bibliotecas Universitárias (CBBU), a Associação Nacional de Pesquisa e Pós-Graduação (ANCIB), a Associação Brasileira de Educação em Ciência da Informação (ABECIN), e a Associação Brasileira de Profissionais da Informação (ABRAINFO).

As editoras e os agregadores de conteúdo são fontes de informação para cotação de preços, licenciamento e aquisição de materiais informacionais impressos ou eletrônicos. As editoras são empresas comerciais responsáveis pelo lançamento das publicações que fornecem materiais informacionais para as 


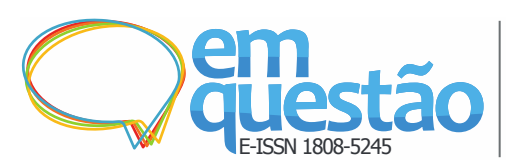

Uso de fontes de informação no monitoramento dos ambientes oraganizacionais: subsídios para o planejamento estratégico em bibliotecas universitárias brasileiras

Everton Rodrigues Barbosa, Raquel Alexandre de Lira, Angel Freddy Godoy Viera e Gregório Varvakis

bibliotecas. Os agregadores de conteúdo são os distribuidores, quando a editora não possui uma plataforma própria (SERRA; SILVA, 2014; CUNHA, 2016).

Para que as BU acompanhem o processo de inovação tecnológica, é preciso notar as tendências do setor. Os diretórios de empresas de tecnologia de informação representam um tipo de fonte de informação para conhecer os serviços e recursos tecnológicos capazes de atender às necessidades informacionais dos usuários de bibliotecas na era digital.

Entre os recursos tecnológicos para a inovação de serviços, França e Carvalho (2014) destacam os softwares de gerenciamento de bibliotecas, aplicativos em dispositivos móveis, sistemas de aquisição e licenciamento de material informacional, especialmente os $e$-books, sistemas de autoempréstimo e devolução, tecnologias assistivas e bases de dados.

Nesse aspecto, os diretórios ou páginas eletrônicas na internet representam um dos tipos de fontes de informação para visualização de oportunidades e ameaças no entorno das BU e para estabelecer parcerias com entidades e empresas.

\subsection{Relatórios de gestão}

Para a elaboração e implementação do plano estratégico, as organizações precisam considerar a participação de todos os setores e de seus membros, pois são esses que, no nível tático, irão desempenhar as ações propostas. Nesse aspecto, conscientizar e orientar a equipe de trabalho na direção das metas estabelecidas é fazer com que as organizações continuem perseguindo o caminho ao qual se propuseram percorrer para atingir seus objetivos organizacionais.

Lion e Gomes (2013) partem da premissa de que a competência básica das BU é o trabalho com a informação, traduzida na focalização da missão, visão e planos da instituição. Tais elementos contribuem para que os bibliotecários gestores e toda a equipe trabalhem ativamente em função do alcance dos objetivos previstos e das metas estabelecidas. 
Ademais, acompanhar, controlar e avaliar as atividades desempenhadas pelas equipes de trabalho produz indicadores, os quais se caracterizam como informação relevante para a tomada de decisão, caso algumas das ações estratégicas não estejam ocorrendo conforme o planejado.

Dessa forma, coletar dados sobre as atividades desenvolvidas no âmbito das bibliotecas permite não somente conhecer o estado de cada unidade de informação, como também acompanhar e avaliar, com base nesses indicadores, se as metas estabelecidas foram alcançadas. Nesse aspecto, a principal fonte para o levantamento desses dados é o relatório de gestão, que, segundo Almeida (2011, p. 39):

[...] é indispensável na coordenação de um sistema de bibliotecas, servindo para o gerenciamento de projetos e para o acompanhamento e avaliação do desempenho tanto das unidades, isoladamente, quanto do sistema como um todo. É com base no conjunto dos relatórios das bibliotecas que a coordenação poderá definir metas para o sistema [...].

Os relatórios de gestão das BU, na maioria das vezes, estão disponíveis nas páginas eletrônicas das universidades. Eles podem se apresentar por meio de uma compilação de indicadores das atividades, organizada por período cronológico específico, que pode variar de um a cinco anos.

Nessa perspectiva, Ferraz (2014) destaca a importância de acompanhar as atividades desenvolvidas pelos setores e membros das bibliotecas capazes de produzir indicadores de gestão, em especial no que diz respeito ao controle e avaliação dos projetos desenvolvidos.

A autora endossa, ainda, que as ferramentas para gestão de projetos podem ser utilizadas para melhorar a qualidade e a eficiência dos processos e disponibilizar novos serviços e produtos, desenvolvidos por meio de projetos alinhados aos objetivos estratégicos da organização, possibilitando um gerenciamento mais eficaz.

De acordo com Rodrigues e Paixão (2016), a aplicação de princípios e técnicas da gestão de projetos permite contribuir para o alcance do sucesso nos projetos desenvolvidos pelas organizações, de forma a gerar uma maior efetividade na execução, controle e acompanhamento das ações estratégicas. 


\subsection{Fontes de informação pessoais: usuários e funcionários}

Nos trabalhos analisados, foi possível identificar a pertinência do uso de fontes de informação pessoais para o PE. Os usuários da informação correspondem às fontes de informação pessoal externas à organização, pois são variáveis do entorno das bibliotecas acadêmicas, enquanto os funcionários ou colaboradores caracterizam-se como fontes de informação pessoal internas, pois estão suscetíveis ao controle imediato da administração das BU.

No tocante às fontes pessoais internas, Paletta e colaboradores (2016) afirmam que os gestores de bibliotecas necessitam fazer consultas permanentes aos seus clientes, buscando identificar quais são suas necessidades informacionais e de que maneira elas podem ser melhor atendidas, para assim desenvolver produtos e serviços de informações eficientes. Nesse sentido, as BU aplicam estudos de uso e de usuários da informação, com o intuito de identificar as características e demandas da comunidade que atendem.

Segundo Sepúlveda e Araújo (2012), conhecer o perfil dos usuários contribui, entre diversas iniciativas, para a formulação de políticas de desenvolvimento de coleções, de serviços de disseminação seletiva da informação e de ações de marketing que oportunizem a promoção da inovação de produtos e serviços de informação.

Os recursos humanos, ou seja, os funcionários ou colaboradores que atuam nas unidades de informação, por sua vez, exercem um papel fundamental no processo de implementação do planejamento estratégico, pois são eles que executam as ações definidas no âmbito organizacional. Assim, as estratégias são formuladas considerando o componente humano.

[...] a estratégia não emerge do nada; pode-se dizer que ela é construída a partir dos problemas e oportunidades e que, dependendo do que ocorre com e ao redor das pessoas (com liberdade e com capacidade de percebê-la), ela é identificada. Para esse caso, a capacidade em percebê-la não requer práticas de formalização ou regras predefinidas, requer basicamente da capacidade de interpretar informações e também da própria 


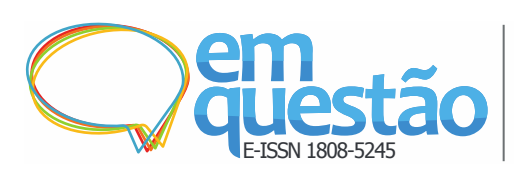

Uso de fontes de informação no monitoramento dos ambientes oraganizacionais: subsídios para o planejamento estratégico em bibliotecas universitárias brasileiras

Everton Rodrigues Barbosa, Raquel Alexandre de Lira, Angel Freddy Godoy Viera e Gregório Varvakis

experiência das pessoas envolvidas nesse processo na organização. (BRITO; ESCRIVÃO FILHO, 2011, p. 102).

As organizações possuem uma estrutura organizacional composta por um quadro de pessoas, distribuídas nos níveis estratégico, tático e operacional. Cada colaborador possui atribuições específicas, dentro da estrutura organizacional, para somar esforços e atingir o objetivo da organização. Para que os objetivos sejam alcançados, os gestores precisam envolvê-los e motiválos a cooperar. (OLIVEIRA, 2013).

Carmo (2008) considera importante a participação das pessoas no desenvolvimento das estratégias organizacionais, pois o sucesso da organização depende do esforço dos gestores no processo de alinhamento das ações da equipe aos objetivos e metas organizacionais definidas no nível macro. Para isso, é preciso motivar o engajamento de todos os membros da organização.

\section{Proposta de categorização das fontes de informação conforme os ambientes organizacionais das BU}

As fontes de informação para a elaboração e implementação de ações estratégicas no âmbito das BU brasileiras foram categorizadas conforme os ambientes organizacionais em que operam.

Desse modo, para fundamentar a proposta de categorização, foi utilizada a reunião das abordagens apresentadas no quadro 1, sumarizando os segmentos e variáveis que se aproximam da realidade de atuação das BU, que culminou nas principais categoriais de fontes de informação distribuídas por segmentos:

a) orientadas ao ambiente geral - representadas pelas diretrizes dos órgãos governamentais reguladores, estabelecidas por leis, resoluções e normas nacionais. Consideramos esses elementos ainda como parte do ambiente geral, pois fornecem informações basilares para implementação e organização das BU. Com vistas a coletar informações relevantes sobre oportunidades, ameaças, inovações e estabelecer parcerias com outras BU, destacam-se os diretórios de bibliotecas, institutos e centros de pesquisa e os congressos e conferências, por meio 


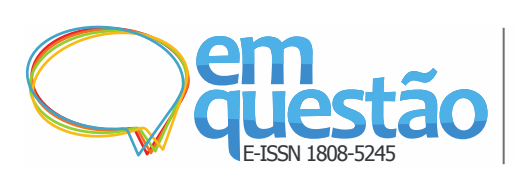

Uso de fontes de informação no monitoramento dos ambientes oraganizacionais: subsídios para o planejamento estratégico em bibliotecas universitárias brasileiras

Everton Rodrigues Barbosa, Raquel Alexandre de Lira, Angel Freddy Godoy Viera e Gregório Varvakis

dos trabalhos publicados em anais de eventos profissionais, pois esses, além de representarem um recurso importante para a educação continuada, são fontes de informação para acompanhar o desenvolvimento de pesquisas e inovação em BU, representados pelos relatos de experiência e estudos de caso. Os diretórios de empresas de tecnologia de informação fornecem informação sobre a seleção de recursos tecnológicos para a promoção de serviços de informação digitais;

b) orientadas ao ambiente organizacional - representadas pelas instituições bibliotecárias, entidades de classe relacionadas à atuação e desempenho profissional, bem como órgãos governamentais, institutos de informação, ciência e tecnologia. Seus principais canais de acesso se configuram como diretórios e sites, que podem servir de fontes de informação para coletar dados do ambiente externo e diagnosticar a situação da BU em relação ao que vem sendo proposto, discutido e desenvolvido na área. Os usuários configuram-se como fontes de informação pessoal internas, pois a partir de suas necessidades de informação, novos produtos e serviços são desenvolvidos;

c) orientadas à percepção do contexto interno - realiza-se a reflexão acerca da visão, dos valores e da missão das IES documentadas no Plano de Desenvolvimento Institucional (PDI) de cada universidade. Ademais, no âmbito interno, os recursos humanos são percebidos nos estudos, como atores sociais fundamentais para a execução das ações, servindo, ainda, como principais fontes de informação para a realização do diagnóstico interno, dada a sua capacidade para gerar indicadores de gestão que, posteriormente, irão compor os relatórios gerenciais das BU, recursos, esses, fundamentais para avaliar, acompanhar e controlar o desenvolvimento das ações estratégicas planejadas. 


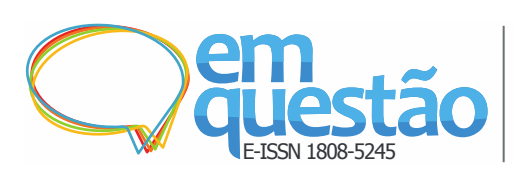

Uso de fontes de informação no monitoramento dos ambientes oraganizacionais: subsídios para o planejamento estratégico em bibliotecas universitárias brasileiras

Everton Rodrigues Barbosa, Raquel Alexandre de Lira, Angel Freddy Godoy Viera e Gregório Varvakis

Quadro 3 - Proposta de categorização das fontes de informação para o monitoramento dos ambientes organizacionais das Bibliotecas Universitárias

\begin{tabular}{|l|l|l|}
\hline Segmentos ambientais & Variáveis ambientais & Fontes de informação \\
\hline Ambiente geral & Econômicas & Legislação \\
& Sociais & Normas \\
& Culturais & Manuais técnicos \\
& Demográficas & Congressos e Conferências \\
& Políticas & Diretórios de bibliotecas, institutos e \\
& Tecnológicas & centros de pesquisa \\
& Legais & Empresas de tecnologia de informação \\
& Ecológicas & \\
\hline Ambiente organizacional & Pessoas & Usuários reais e potenciais \\
& Grupos de pessoas & Diretórios de entidades de classe \\
& Entidades & Diretórios e catálogos de editoras \\
& Empresas & Empresas de tecnologia de informação \\
& Órgãos governamentais & Ministério da Educação \\
\hline Ambiente interno & Redes de comunicação & Relatórios de Gestão \\
& Produção & Planos de Desenvolvimento \\
& Marketing & Institucional \\
& Recursos humanos & Funcionários e colaboradores \\
\hline
\end{tabular}

Fonte: Elaborado pelos autores.

O quadro 2 apresenta a lista com as fontes de informação evidenciadas nos trabalhos analisados. Percebe-se que algumas fontes de informação podem ser utilizadas no monitoramento de mais de um segmento ambiental, como as empresas de tecnologia de informação, que fornecem informações úteis para a seleção e manutenção de recursos tecnológicos.

\section{Considerações finais}

Os estudos analisados demonstraram que as fontes de informação para o PE em BU brasileiras apresentam diferentes tipologias. Os múltiplos fatores que influenciam suas formas de uso estão condicionados às variáveis dos ambientes organizacionais internos e externos.

Foram identificadas fontes documentais, pessoais e institucionais, entre as quais se destacaram as leis, diretrizes, manuais técnicos, políticas de desenvolvimento institucional, relatórios de gestão, diretórios, congressos e conferências que, potencialmente, contribuem para o monitoramento dos ambientes geral, organizacional e interno.

A análise de citação dos artigos de periódicos e anais de eventos revelaram as fontes de informação e os autores mais utilizados para a discussão 
e elaboração do PE em BU, destacando-se os livros sobre planejamento, gestão e organização de bibliotecas e os artigos na modalidade de estudos de caso e relatos de experiência publicados em eventos da área.

Foi possível evidenciar que as publicações governamentais, especialmente aquelas que estabelecem diretrizes, leis e decretos, representaram um recurso de informação frequentemente utilizado no PE, tendo em vista que as BU necessitam atuar de acordo com a regulamentação do MEC.

Outrossim, os relatórios de gestão e os PDIs das instituições foram considerados fundamentais, pois, para avaliar a qualidade dos serviços nas BU, é importante verificar se seus bens e serviços estão alinhados às políticas e à filosofia da instituição, sendo necessário consultar os documentos que formalizam a missão, os valores e as metas das IES nas quais as BU estão inseridas.

Desse modo, espera-se que o presente estudo possa contribuir para a seleção de fontes de informação mais apropriadas, direcionadas à fundamentação, elaboração de projetos e ações estratégicas no âmbito das BU brasileiras.

Recomenda-se, ainda, que as discussões sobre as categoriais de fontes de informação sejam aprofundadas em trabalhos futuros, considerando sua efetiva aplicabilidade no monitoramento ambiental e planejamento estratégico.

\section{Agradecimentos}

À Profa. Dra. Ursula Blattmann, que contribuiu com a elaboração do presente artigo por meio da ministração da disciplina Fontes de Informação, do Programa de Pós-graduação em Ciência da Informação da Universidade Federal de Santa Catarina.

\section{Referências}

ALMEIDA, M. C. B. Planejamento de bibliotecas e serviços de informação. 2. ed. Brasília: Briquet de Lemos, 2011.

ALMEIDA, M. I. R. Por que não desenvolver uma análise ambiental para o 


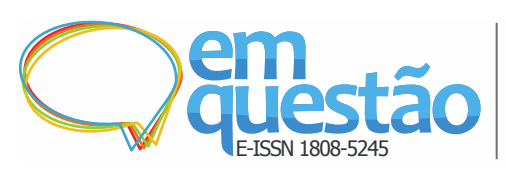

Uso de fontes de informação no monitoramento dos ambientes oraganizacionais: subsídios para o planejamento estratégico em bibliotecas universitárias brasileiras

Everton Rodrigues Barbosa, Raquel Alexandre de Lira, Angel Freddy Godoy Viera e Gregório Varvakis

planejamento estratégico que tenha lógica e não seja apenas um agrupamento de informações. In: ENCONTRO DA ASSOCIAÇÃO NACIONAL DE PÓSGRADUAÇÃO E PESQUISA EM ADMINISTRAÇÃO, 21., 1997, Rio das Pedras. Anais eletrônicos... Rio das Pedras: ANPAD, 1997.

ASSOCIAÇÃO BRASILEIRA DE EDUCAÇÃO EM CIÊNCIA DA INFORMAÇÃO. Marília, 2016.

ASSOCIAÇÃO BRASILEIRA DE NORMAS TÉCNICAS. NBR ISO

9001:2015: sistemas de gestão da qualidade - requisitos. São Paulo, 2015.

ASSOCIAÇÃO BRASILEIRA DE PROFISSIONAIS DA INFORMAÇÃO. 2017. Portal da ABRAINFO.

ASSOCIAÇÃO NACIONAL DE PESQUISA E PÓS-GRADUAÇÃO EM CIÊNCIA DA INFORMAÇÃO. [2017].

BARBÊDO, S. A. D. Aplicação do benchmarking em bibliotecas: resultados, desafios e propostas. Itajubá: UNIFEI, 2002.

BARBOSA, R. R. Uso de fontes de informação para a inteligência competitiva: um estudo da influência do porte das empresas sobre o comportamento informacional. Encontros Bibli, Florianópolis, n. esp., 1. sem., p. 91-102, jul. 2006.

BEHR, A.; MORO, E. L. S.; ESTABEL, L. B. Uma proposta de atendimento às necessidades de informação dos usuários da biblioteca escolar por meio do benchmarking e do sensemaking. Informação \& Informação, Londrina, v. 15, n. 1, p. 37-54, jan./jun. 2010.

BRASIL. Ministério da Educação. Lei n. 9.394, de 20 de dezembro de 1996. Estabelece as Diretrizes de Base da Educação Nacional (LDB). Brasília, 1996.

BRASIL. Secretaria de Educação Superior. Manual de verificação in loco das condições institucionais. Brasília, 2002.

BRASIL. Ministério da Educação. Portaria n. 1.382, de 31 de outubro de 2017. Aprova, em extratos, os indicadores dos Instrumentos de Avaliação Institucional Externa... Brasília, DF, 2017a.

BRASIL. Ministério da Educação. Portaria no 1.383, de 31 de outubro de 2017. Aprova, em extrato, os indicadores do Instrumento de Avaliação de Cursos de Graduação... Brasília, DF, 2017b.

BRASIL. Ministério da Educação. Instrumento de avaliação institucional externa presencial e a distância. Brasília, 2017c. 


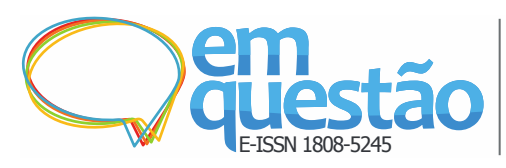

Uso de fontes de informação no monitoramento dos ambientes oraganizacionais: subsídios para o planejamento estratégico em bibliotecas universitárias brasileiras

Everton Rodrigues Barbosa, Raquel Alexandre de Lira, Angel Freddy Godoy Viera e Gregório Varvakis

BRASIL. Ministério da Educação. Instruções para a elaboração do plano de desenvolvimento institucional: artigo 16 do decreto $\mathrm{n}^{\circ} 5.773$ de 09 de maio de 2006. Brasília: Ministério da Educação, 2007. Atualizado em 05/06/2007.

BRITO, A. G. C.; ESCRIVÃO FILHO, E. Fontes de informação formal e informal no processo estratégico: estudo de casos em empresas hoteleiras da região central do estado de São Paulo. Gestão da Produção, Operações e Sistemas, Bauru, ano 6, n. 1, p. 101-117, jan./mar. 2011.

CARMO, T. V. P. Inovação enfatizada no planejamento estratégico de TI: estudo de caso em uma organização baseada em TI. 2008. Monografia (Graduação de Ciência da Computação) - Universidade Federal de Lavras, Lavras, 2008.

CARVALHO, M. M. M. O serviço experiencial em bibliotecas universitárias. 2016. Tese (Doutorado em Gestão) - Universidade de Trás-osMontes e Alto Douro, Vila Real, 2016.

CARVALHO, N. M. S. Empreendedorismo em bibliotecas universitárias: a excelência do atendimento na Biblioteca Central da Universidade Federal de Sergipe. In: SEMINÁRIO NACIONAL DE BIBLIOTECAS

UNIVERSITÁRIAS, 15., 2008, São Paulo. Anais... São Paulo: Conselho de Reitores das Universidades Estaduais Paulistas, 2008.

CENDÓN, B. V. et al. Ciências da informação e biblioteconomia: novos conteúdos e espaços de atuação. Belo Horizonte: UFMG, 2005.

CERTO, S.; PETER, J. P. Administração estratégica: planejamento e implementação da estratégia. 3. ed. São Paulo: Pearson Prentice Hall, 2010.

CHIAVENATO, I. Introdução à teoria geral da administração. São Paulo: Makron, 2011.

CHOO, C. W. A organização do conhecimento: como as organizações usam a informação para criar significado, construir conhecimento e tomar decisões. 3. ed. São Paulo: Senac, 2011.

COBBE, P. R. C. O. Inteligência organizacional no apoio à gestão acadêmica de IES privadas. 2013. Dissertação (Mestrado em Gestão do Conhecimento e Tecnologia da Informação) - Universidade Católica de Brasília, Brasília, 2013.

COBBE, P. R. C. O. et al. A inteligência organizacional como instrumento de auto avaliação em instituições de ensino superior. Perspectivas em Gestão \& Conhecimento, João Pessoa, v. 5, n. 2, 2015.

COMISSÃO BRASILEIRA DE BIBLIOTECAS UNIVERSITÁRIAS. 2017. Blog da Comissão. 


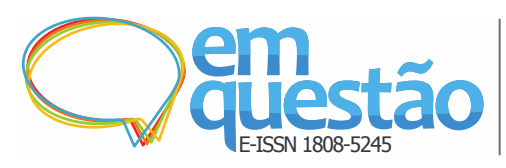

Uso de fontes de informação no monitoramento dos ambientes oraganizacionais: subsídios para o planejamento estratégico em bibliotecas universitárias brasileiras

Everton Rodrigues Barbosa, Raquel Alexandre de Lira, Angel Freddy Godoy Viera e Gregório Varvakis

CUNHA, M. B. Para saber mais: fonte de informação em ciência e tecnologia. 2. ed. Brasília: Brinquet de Lemos, 2016.

DAVENPORT, T. H. Ecologia da informação. São Paulo: Futura, 1998.

DI FOGGI, R. A.; COLETTA, T. G.; CRISTIANINI, G. M. S. Planejamento estratégico em bibliotecas universitárias estatuais públicas do estado de São Paulo: análise, avaliação e proposta de um roteiro. In: SEMINÁRIO NACIONAL DE BIBLIOTECAS UNIVERSITÁRIAS, 16., 2010, Rio de Janeiro. Anais... Rio de Janeiro: UFRJ, 2010.

FARIA, M. M. de; GADELHA, M. M. A gestão da informação na biblioteca universitária como ferramenta auxiliar ao planejamento estratégico: um exemplo de análise de impacto. Revista Conhecimento em Ação, Rio de Janeiro, v. 1, n. $1,2016$.

FRANÇA, M. N.; CARVALHO, A. M. G. de. Gestão de bibliotecas universitárias: tendências tecnológicas nas universidades públicas brasileiras. In: c, 18., 2014, Belo Horizonte. Anais... Belo Horizonte: UFMG , 2014.

FEDERAÇÃO BRASILEIRA DE ASSOCIAÇÕES DE BIBLIOTECÁRIOS E CIENTISTAS DA INFORMAÇÃO. São Paulo, 2017.

FERRAZ, K. M. de A. Implantação de um Sistema De Gestão De Projetos na Divisão de Biblioteca (DIBD) da Escola Superior de Agricultura "Luiz de Queiroz" (ESALQ). In: SEMINÁRIO NACIONAL DE BIBLIOTECAS UNIVERSITÁRIAS, 18., 2014, Belo Horizonte. Anais eletrônicos... Belo Horizonte, MG: UFMG, 2014.

FUNDAÇÃO BIBLIOTECA NACIONAL. Rio de Janeiro, 2017.

GIANESI, I.; CORRÊA, H. L. Administração estratégica de serviços: operações para a satisfação do cliente. São Paulo: Atlas, 2009.

GLUECK, W. F. Business policy strategy information and management action. New York: Mc Graw-Hill, 1976.

GOMES, L.; BARBOSA, M. Impacto da aplicação das tecnologias da informação e comunicação (TICs) no funcionamento das bibliotecas universitárias. In: ENCONTRO NACIONAL EM CIÊNCIA DA INFORMAÇÃO, 4., 2003, Salvador. Anais eletrônicos... Salvador: UFBA, 2003.

HITT, M. A.; IRELAND, R. D.; HOSKISSON, R. E. Administração estratégica: competitividade e globalização. 2. ed. São Paulo: Cengage Learning, 2011. 


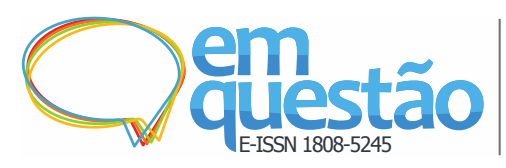

Uso de fontes de informação no monitoramento dos ambientes oraganizacionais: subsídios para o planejamento estratégico em bibliotecas universitárias brasileiras

Everton Rodrigues Barbosa, Raquel Alexandre de Lira, Angel Freddy Godoy Viera e Gregório Varvakis

INSTITUTO BRASILEIRO DE INFORMAÇÃO EM CIÊNCIA E TECNOLOGIA. [Missão]. Brasília, 2017.

INSTITUTO NACIONAL DE ESTUDOS E PESQUISAS EDUCACIONAIS. Censo da Educação Superior 2016: principais resultados do Censo da Educação Superior 2016. Brasília, 2017.

INTERNATIONAL ORGANIZATION FOR STANDARDIZATION. ISO 11620:2014: information and documentation - library performance indicators. Geneva: ISO, 2014.

LION, S. E. K.; GOMES, H. F. Eficiência estratégica na gestão de bibliotecas universitárias: um estudo sobre o sistema de Bibliotecas da Universidade Federal da Bahia (SIBI/UFBA). In: ENCONTRO NACIONAL DE PESQUISA EM CIÊNCIA DA INFORMAÇÃO, 14., 2013, Florianópolis,. Anais eletrônicos... Florianópolis: UFSC, 2013.

LIRA, R. A. Planejamento estratégico para o sistema de Bibliotecas da Universidade Federal do Amazonas: proposta de modelo. Manaus: Edua, 2015.

LUBISCO, N. M. L. Bibliotecas universitárias, seus serviços e produtos: transposição de um modelo teórico de avaliação para um instrumento operacional - relatório de pesquisa I. PontodeAcesso, Salvador, v. 8, p. 80-141, 2014.

MATUS, C. Confusión sobre la planificación. In: HUERTAS, B. Franco. Planificar para gobernar: el Método PES: entrevista a Carlos Matus. Buenos Aires: Fundación CiGob, 2016. p. 5-16.

MILLER, D. The structural and environmental correlates of business strategy. Strategic managent journal, Hoboken, v. 8, n. 1, p. 55-76, 1987.

NARAYANAN, V. K.; FAHEY, Liam. Macroenvironmental analysis: understanding the environment outside the industry in the portable MBA in Strategy. Hoboken: John Wiley \& Sons, 1994.

OLIVEIRA, D. P. R. O planejamento estratégico: conceitos, métodos e práticas. 31. ed. São Paulo: Atlas, 2013.

OLIVEIRA, L. R. Biblioteca universitária: uma análise sobre os padrões de qualidade atribuídos pelo Ministério da Educação ao contexto brasileiro. 2004. 123f. Dissertação (Mestrado em Ciência da Informação) - Pontifícia Universidade Católica de Campinas, 2004.

PALETTA, F. C. et al. Estudos de usuário e o planejamento dos serviços de informação em biblioteca. Revista ACB, Florianópolis, v. 21, n. 1, p. 145-155, dez./mar. 2016. 


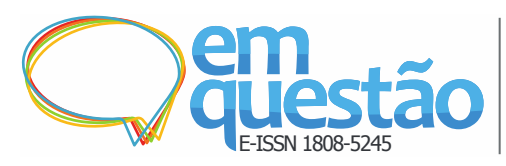

Uso de fontes de informação no monitoramento dos ambientes oraganizacionais: subsídios para o planejamento estratégico em bibliotecas universitárias brasileiras

Everton Rodrigues Barbosa, Raquel Alexandre de Lira, Angel Freddy Godoy Viera e Gregório Varvakis

PEREZ RODRIGUEZ, Y.; MILANES GUISADO, Y. La biblioteca universitária: reflexiones desde una perspetiva atual. ACIMED, Ciudad de La Habana, v. 18, n. 3, 2008.

PIMENTA, E. C. T.; COELHO JÚNIOR, T. P. O uso de indicadores de desempenho da ISO 11620 para avaliar bibliotecas universitárias. In: SEMINÁRIO NACIONAL DE BIBLIOTECAS UNIVERSITÁRIAS, 19., 2016, Manaus. Anais eletrônicos... Manaus: UFAM, 2016.

RODRIGUES, R.; PAIXÃO, C. H. A importância do planejamento estratégico na Gestão de projetos. In: CONGRESSO NACIONAL DE EXCELÊNCIA EM GESTÃO, 12., 2016, Rio de Janeiro. Anais eletrônicos... Rio de Janeiro, 2016.

SEPÚLVEDA, M. I. M.; ARAÚJO, C. A. A. Realização de estudos de usuários na prática profissional bibliotecária: estudo de caso do sistema de bibliotecas da UFMG. Revista ACB, Florianópolis, v. 17, n. 2, p. 269-287, set. 2012.

SERRA, L. G.; SILVA, J. F. M. Licenciamento de livros eletrônicos e o modelo de negócio DDA (Demand Driven Acquisition). In: SEMINÁRIO NACIONAL DE BIBLIOTECAS UNIVERSITÁRIAS, 18., 2014, Belo Horizonte. Anais eletrônicos... Belo Horizonte: UFMG, 2014. p. 2079-2084.

SHOID, M. S. M.; KASSIM, N. A. Ascertaining Dimensions of Organizational Learning Capabilities (OLC) in academic library. International Journal of Academic Research in Business and Social Sciences, Pakistan, v. 3, n. 7, p. 546-554, 2013.

VASCONCELLOS FILHO, P. de. Análise ambiental para o planejamento estratégico. Revista de administração de empresas, São Paulo, v. 19, n. 2, p. 115-127, jun. 1979.

WATSON, L. The future of the library as a place of learning: a personal perspective. New Review of Academic Librarianship, Abingdon-on-Thames, v. 16, n. 1 , p. $45-56,2010$.

\section{Use of information sources in the organizational environment monitoring: subsidies for strategic planning in Brazilian university libraries}

Abstract: The study aims to propose an information sources categorization for
the organizational environments monitoring of University Libraries, considering
these informational resources as a tool to provide subsidies for the strategic
planning. It discusses the environmental variables that influence the Brazilian 


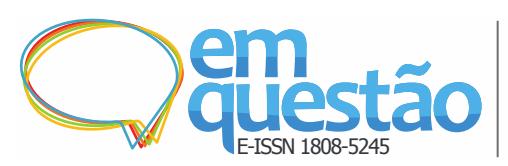

Uso de fontes de informação no monitoramento dos ambientes oraganizacionais: subsídios para o planejamento estratégico em bibliotecas universitárias brasileiras

Everton Rodrigues Barbosa, Raquel Alexandre de Lira, Angel Freddy Godoy Viera e Gregório Varvakis

academic libraries management. The research is characterized as exploratory descriptive, qualitative and quantitative approach, and uses bibliographical research for the publications survey. It presents the main sources, works and authors mentioned in the analyzed literature. It concludes that the information sources can be categorized according to three environmental segments: the first focused on the perception of the general environment, the second on the organizational environment, and the third on the internal environment. It recommends future work to deepen approaches of information sources categories, considering its effective applicability in environmental monitoring and strategic planning.

Keywords: Information sources. Organizacional environment. Strategic planning. University libraries.

Recebido: $15 / 03 / 2018$

Aceito: $10 / 07 / 2018$

${ }^{1} \mathrm{O}$ quantitativo das publicações mais citadas diverge da quantidade de autores mais citados, pois, enquanto o Quadro 1 revela a quantidade de citações feitas a uma única obra, a Tabela 2 apresenta o número de menções feitas a diversas publicações em que o autor aparece. 